\title{
Comment on: Nyirenda MJ, Dean S, Lyons V, Chapman KE, Seckl JR (2006) Prenatal programming of hepatocyte nuclear factor $4 a$ in the rat: a key mechanism in the 'foetal origins of hyperglycaemia'? Diabetologia 49: 1412-1420, and on: McCurdy CE, Friedman JE (2006) Early foetal programming of hepatic gluconeogenesis: glucocorticoids strike back. Diabetologia 49:1138-1141
}

\author{
S. P. Burns • R. D. Cohen \\ Received: 4 July 2006 / Accepted: 6 July 2006/ Published online: 19 September 2006 \\ (C) Springer-Verlag 2006
}

Nyirenda et al. present compelling new evidence on the mechanism of fetal programming of gluconeogenesis by glucocorticoid administration during the last third of pregnancy in rats [1], a study that is commented on by McCurdy and Friedman [2]. Nyirenda et al. focus on a fluxgenerating enzyme of gluconeogenesis (phosphoenolpyruvate carboxykinase [PCK]) and the factors involved in its transcription, showing how $P C K$ mRNA and that of its controlling transcription factors are localised within the hepatic acinus.

However, this picture is incomplete. It is known that under normal conditions gluconeogenesis is mainly periportal, and about $24 \%$ of the new glucose formed is re-taken up in the perivenous cells, which are rich in the enzyme glucokinase. In the adult offspring of rat dams subjected to restricted protein intake during pregnancy and lactation, the perivenous uptake of glucose is much decreased, and the activity of total glucokinase (both free and bound to glucokinase regulatory protein in the nucleus) is greatly

S. P. Burns

Department of Biological Sciences, University of Huddersfield, Huddersfield HD1 3DH, UK

\section{R. D. Cohen $(\bowtie)$}

Queen Mary School of Medicine, University of London,

Whitechapel Road, London E1 1BB, UK

e-mail: rcohen@doctors.org.uk reduced $[3,4]$, leading eventually to glucose intolerance-a possible model of type 2 diabetes in man. Glucokinase transcription, however, is unchanged in these programmed offspring, suggesting an effect on nucleo-cytoplasmic transport of glucokinase, which resides in the nucleus in the starved state but translocates to the cytosol postprandially. The difficulty in attributing control of gluconeogenesis to transcriptional events is that they are too slow [4] to provide the rapid switch-off of hepatic glucose output and the hepatic storage of glucose as glycogen seen in the postprandial state. A further effect of rats fetally programmed by maternal protein restriction is that the hepatic acini are enlarged to about twice the normal volume. Large lobules are also seen in pregnancy and in regenerating liver after partial hepatectomy in the rat $[5,6]$. The consequences of this enlargement are unknown but it would be of interest to determine whether the same enlargement occurs in animals fetally programmed by glucocorticoids.

\section{References}

1. Nyirenda MJ, Dean S, Lyons V, Chapman KE, Seckl JR (2006) Prenatal programming of hepatocyte nuclear factor $4 \mathrm{a}$ in the rat: a key mechanism in the 'foetal origins of hyperglycaemia'? Diabetologia 49:1412-1420

2. McCurdy CE, Friedman JE (2006) Early foetal programming of hepatic gluconeogenesis: glucocorticoids strike back. Diabetologia 49:1138-1141

3. Burns SP, Desai M, Cohen RD et al (1997) Gluconeogenesis, glucose handling, and structural changes in livers of the adult offspring of rats partially deprived of protein during pregnancy and lactation. J Clin Invest 100:1768-1774 
4. Murphy HC, Regan G, Bogdarina IG et al (2003) Fetal programming of perivenous glucose uptake reveals a regulatory mechanism governing hepatic glucose output during refeeding. Diabetes 52:1326-1332

5. Martin-Pont B, Tamboise E (1984) Quantitative cytologic and histologic study of the maternal hepatocyte and lobule on the 18th day of gestation in the Wistar rat. Bull Assoc Anat (Nancy) 68: 23-40

6. Waganaar GTM, Chamuleau RAFM, Pool CW et al (1993)

Distribution and activity of glutamine synthase upon enlargement of the liver lobule by repeated partial hepatectomies. J Hepatol $17: 397-407$ 